\title{
REASSENTAMENTO DA POPULAÇÃO URBANA DIRETAMENTE AFETADA PELO EMPREENDIMENTO HIDRELÉTRICO DE BELO MONTE EM ALTAMIRA-PA
}

\author{
José Queiroz de Miranda Neto ${ }^{1}$
}

\begin{abstract}
RESUMO
O presente trabalho aborda o processo de reassentamento da população urbana diretamente afetada pelo empreendimento hidrelétrico de Belo Monte em Altamira-PA. Para fins de análise, considera as características socioambientais das áreas de origem (Área Diretamente Afetada), o processo de seleção das áreas de destino, (Reassentamento Urbano Coletivo) e os projetos de Reurbanização nas Áreas remanescentes da ADA Urbana. Como metodologia, são utilizados os estudos de avaliação de impactos e relatórios técnicos apresentados pela Norte Energia S.A, além de informações coletadas em campo, como fotos e dados obtidos em pontos específicos da cidade. $O$ resultado apresenta um quadro positivo para a população afetada na área urbana, que deve deixar ocupações de risco e residir em áreas com melhores condições de habitabilidade. Contudo, outras questões devem ser avaliadas, como o crescimento populacional da cidade e o risco de novas ocupações irregulares, bem como a ausência de políticas permanentes de habitação para as populações não diretamente afetadas.
\end{abstract}

PALAVRAS-CHAVE: Reassentamento. usina hidrelétrica. espaço urbano.

\section{RESETTLEMENT OF URBAN POPULATION DIRECTLY AFFECTED BY THE BELO MONTE HYDROELECTRIC PROJECT IN ALTAMIRA-PA}

\begin{abstract}
This paper discusses the process of resettlement of urban population directly affected by the Belo Monte hydroelectric project in Altamira-PA. For this analysis, will be considered the social and environmental characteristics of the areas of origin (Directly Affected Area), the process of selection of target areas, (Resettlement Urban Collective) and the remaining projects in the Redevelopment Areas. As a methodology, studies of impact assessment and technical reports submitted by Norte Energia SA are used, and information collected in the field, such as photos and data from specific points of the city. The result shows a positive framework for the affected population in the urban area, which should
\end{abstract}

\footnotetext{
${ }^{1}$ Mestre em Geografia, docente e pesquisador na Faculdade de geografia da Universidade Federal do Pará. Aluno do Programa de pós-graduação em Geografia da FCT/UNESP mirandaneto@ufpa.br
} 


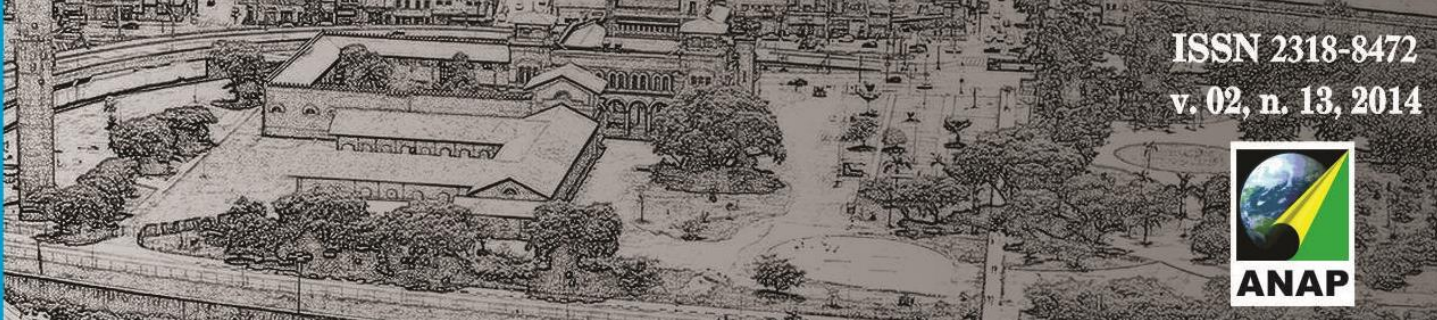

Revista Nacional de

Gerenciamento de Cidades

make risk occupations and live in areas with better living conditions. However, other issues should be evaluated, as the population growth of the city and the risk of new irregular occupations, as well as the lack of permanent housing policies for populations not directly affected.

KEY-WORDS: resettlement. hydroelectric project. Urban Space.

\title{
REASENTAMIENTO DE LA POBLACIÓN URBANA
}

\author{
AFECTADA DIRECTAMENTE POR EL PROYECTO \\ HIDROELÉCTRICO DE BELO MONTE, EN ALTAMIRA-PA
}

\begin{abstract}
RESUMEN
En este trabajo se analiza el proceso de reasentamiento de la población urbana afectada directamente por el proyecto hidroeléctrico de Belo Monte, en Altamira-PA. Para este análisis, se tendrán en cuenta las características sociales y ambientales de las zonas de origen (zona directamente afectada), el proceso de selección de las zonas de destino, (Reasentamiento Colectivo Urbano) y los proyectos que quedan en las áreas de reurbanización. Como metodología, se utilizan los estudios de evaluación del impacto y los informes técnicos presentados por Norte Energia S.A y la información recogidos en el campo, tales como fotos y datos de los puntos específicos de la ciudad. El resultado muestra un marco positivo para la población afectada en el área urbana, lo que debería hacer ocupaciones de riesgo y vivir en áreas con mejores condiciones de vida. Sin embargo, otros temas deben ser evaluados, ya que el crecimiento de la población de la ciudad y el riesgo de nuevas ocupaciones irregulares, así como la falta de políticas de vivienda permanente para las poblaciones no afectadas directamente.
\end{abstract}

PALABRAS-CLAVE Reasentamiento. Proyecto hidroeléctrico. Espacio urbano.

\section{INTRODUÇÃO}

O presente trabalho pretende abordar o processo de reassentamento da população urbana diretamente afetada pelo empreendimento hidrelétrico de Belo Monte em Altamira-PA. Tendo em vista a complexidade do processo, serão considerados três pontos fundamentais para a análise em questão: as características socioambientais das áreas de origem, compondo a Área Urbana Diretamente Afetada (ADA Urbana), o processo de seleção das áreas de destino, denominados de Reassentamentos Urbanos Coletivos (RUC) e os projetos de 


\section{Revista Nacional de}

Reurbanização nas Áreas remanescentes da ADA Urbana. Pretende-se, também, inferir sobre a atuação do Comitê de Acompanhamento do Reassentamento Urbano Coletivo e avaliar o processo de mudança das famílias da ADA Urbana para as RUC.

Trata-se, portanto, de uma grande ação de intervenção urbana com impacto direto na habitação, uma vez que, por um lado, envolve a mudança do local de moradia de mais de 22 mil pessoas e, por outro, mobiliza grandes projetos de engenharia no contexto da cidade, como a construção de 6.000 unidades habitacionais e reurbanização de mais de 500 hectares. Nos aspectos social e ambiental, é possível identificar impactos positivos e negativos do empreendimento, alguns dos quais serão relatados ao final deste.

Para elaboração deste trabalho, são utilizados os estudos de avaliação de impactos e relatórios técnicos apresentados pela Norte Energia S.A, empresa responsável por todas as etapas do processo de reassentamento. Além desses documentos, algumas informações foram coletadas em campo, como fotos e dados obtidos em pontos específicos da cidade, com vistas a subsidiar o assunto em questão.

\section{A HABITAÇÃO EM ALTAMIRA: ANÁLISE DO CONTEXTO}

O processo de ocupação e a consequente urbanização da cidade de Altamira se deram sob o contexto da colonização da Amazônia em períodos distintos da história. A área onde se localiza atualmente o centro histórico da cidade, nas proximidades do Igarapé Ambé, foi ocupado a partir da penetração das primeiras missões jesuíticas no médio rio Xingu, onde foram erguidos templos religiosos, colégios e habitações necessárias ao trabalho da igreja (UMBUZEIRO \& UMBUZEIRO, 2012). Mas tarde, com o advento da economia da borracha no Séc. 


\section{Revista Nacional de}

XIX, a pequena localidade ganha maior expressão e a vila é transformada oficialmente em cidade-sede do recém-criado município de Altamira, em 1917.

Com o processo de integração da Amazônia à economia nacional, a partir de 1960, uma forte leva de migrantes é atraída para a cidade, sobretudo com a criação da rodovia transamazônica (BR-230). Através dos projetos de colonização incentivados pelo INCRA, mais de seis mil pessoas foram assentadas na região até 1980 (BECKER, 1997), os quais seriam atendidos pelo governo em suas necessidades de produção. Porém, com as crises que abalaram a economia nacional, a colonização dirigida foi deixada de lado e muitos migrantes passaram a se dirigir à cidade de Altamira. Com isso, o crescimento da população urbana foi significativo, passando de 5.374 em 1970 para 26.911 em 1980, multiplicando cinco vezes em apenas uma década. Em 2010, a população da cidade já atinge mais de 75 mil habitantes (IBGE, 2010a) e continua crescendo de forma acelerada pela atração exercida dos novos empreendimentos.

Tal crescimento esteve acompanhado de uma ocupação urbana sem planejamento, pois muitas famílias fixaram residência em áreas de alagamento próximas aos igarapés Altamira e Ambé. Tais ocupações se deram, em grande parte, a partir da construção de residências em palafitas, com sistemas de saneamento precário ou inexistente, motivando o despejo de esgoto residencial diretamente no rio. Com as crises sucessivas no campo e a consequente migração rural-urbana, outras frentes de migrantes passaram a ocupar a cidade em áreas ainda mais inadequadas, a exemplo da "Invasão dos Padres" (Fig. 1). O censo demográfico de 2010 aponta a presença de mais de 9 mil pessoas residindo em aglomerados subnormais em Altamira, que seriam caracterizados pela irregularidade das vias de circulação e do tamanho e forma dos lotes, além de carência de serviços públicos essenciais, como: coleta de lixo, rede de esgoto, rede de água, energia elétrica e iluminação pública (IBGE, 2010b). 


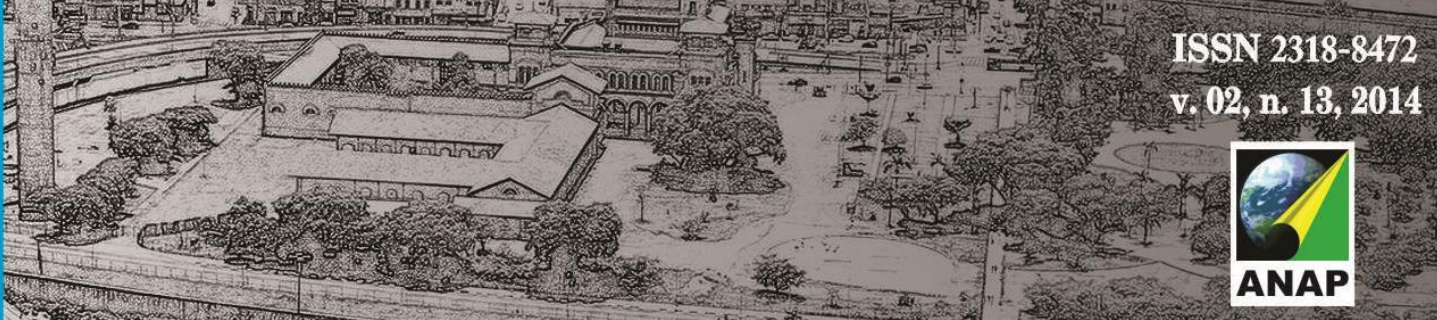

Revista Nacional de

Gerenciamento de Cidades
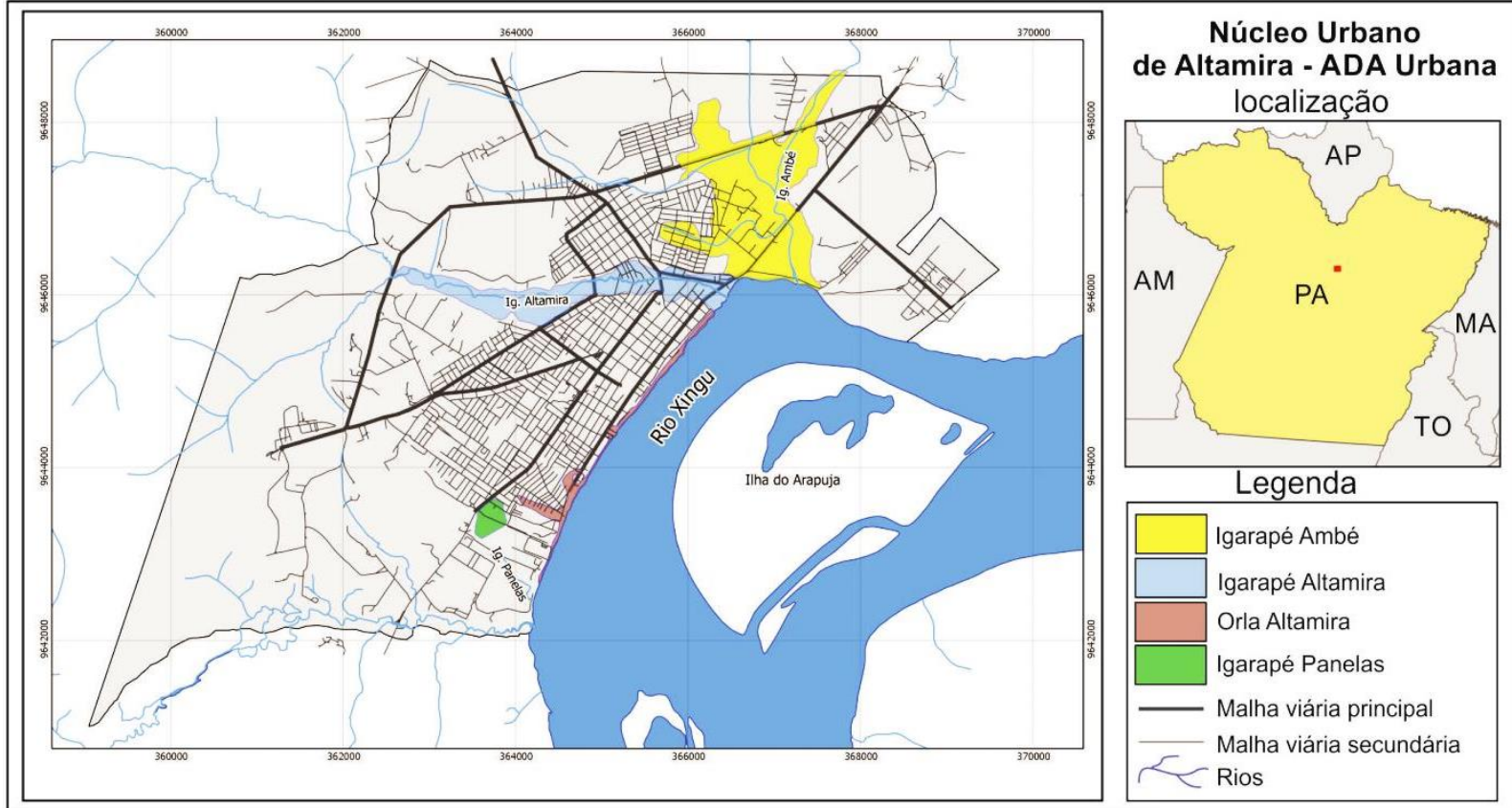

Mapa 01. Núcleo Urbano de Altamira - Área Diretamente Afetada Urbana Fonte: Base cartográfica do IBGE (2011) e Norte Energia S.A (2012)

Grande parte dos domicílios localizados na ADA Urbana apresentam condições de habitabilidade precárias, a exemplo da situação do esgotamento sanitário. No conjunto das áreas afetadas, do total de 5.241 famílias apenas 54 possuem fossa séptica, enquanto que 2.706 possuem fossa rudimentar, 1.176 ligadas a uma vala negra e 518 não possuem nenhum tipo de instalação. Tal situação representa, por um lado, o legado histórico de ocupações irregulares na cidade de Altamira e, por outro, a ausência de políticas públicas efetivas relacionadas à habitação. $O$ quadro habitacional evidente em Altamira não difere de muitas cidades do Estado do Pará, a exemplo de Marabá, Santarém e Tucuruí, que juntos somam mais de 100 mil pessoas em situação semelhante (IBGE, 2010b).

Segundo o ESTATUTO DAS CIDADES (Lei № 10.257 / 2001), uma dos principais problemas identificados em periferias urbanas brasileiras é o processo de "favelização", que está diretamente ligado ao uso do solo. No caso da ADA Urbana, devido ao processo de ocupação desordenada, de 7.790 cadastros realizados, apenas $3,3 \%$ possuem escritura registrada. Tal fato se dá pela natureza das 


\section{Revista Nacional de}

ocupações, situadas geralmente em zonas onde há restrição de uso por construções. A citação abaixo sintetiza a situação evidente em Altamira e, também, presente em milhares de áreas similares no Brasil e na Amazônia:

As áreas ambientalmente frágeis - margens de córregos, rios e reservatórios, encosta íngremes, mangues, áreas alagáveis, fundos de vales - que, por essa condição, merecem legislação específica e não interessam ao mercado legal, são as que "sobram" para a moradia de grande parte da população. (MINISTÉRIO DAS CIDADES, 2007. Mod. II, p 03).

Existe, contudo, um conjunto de fatores negativos relacionados às ocupações em áreas ambientalmente frágeis, especialmente ligadas à saúde e a qualidade de vida. Vários estudos, a exemplo de Teixeira e Heller (2005) associam a prevalência de diarreia em crianças com as condições ambientais presentes em áreas subnormais como fatores de risco coletivo, a exemplo do consumo de água de mina, o contato com esgoto e acondicionamento inadequado do lixo. No caso de Altamira, o processo de reassentamento urbano e a consequente eliminação das áreas de risco, podem ser fator de impacto positivo para essas populações, tendo em vista o conjunto de processos que veremos a seguir.

\section{USINA HIDRETELÁTRICA E REASSENTAMENTO URBANO}

A Usina Hidrelétrica de Belo Monte está sendo construída no Rio Xingu, com potência instalada de $11.233 \mathrm{MW}$. Será a maior usina hidrelétrica inteiramente brasileira e a terceira maior hidrelétrica do mundo. $O$ reservatório ${ }^{2}$ da usina abrangerá uma área de $516 \mathrm{~km}^{2} \mathrm{e}$, segundo o Relatório de Impacto Ambiental (RIMA), inundará áreas habitadas dos municípios de Altamira, Vitória do Xingu e Brasil Novo. No caso de Altamira, o conjunto de áreas diretamente afetadas corresponde em torno de $25 \%$ da malha urbana da cidade. Nesse caso, as

\footnotetext{
2 Belo Monte é uma usina hidrelétrica a fio d'água. De acordo com o RIMA (2009) tratam-se de "reservatórios que não possuem função de regularização de vazões, não armazenando água. Assim, geram energia a partir da vazão natural do rio".
} 


\section{Revista Nacional de}

residências localizadas abaixo da cota altimétrica de 100 metros deverão ser indenizadas conforme a modalidade escolhida (em dinheiro, carta de crédito ou reassentamento) e os espaços remanescentes transformados em parques ou reurbanizados.

A opção pelo tipo de indenização é feita pela própria família residente, a partir do cadastro realizado pela Norte Energia S.A durantes o processo de negociação. Para o caso de indenização em dinheiro ou carta de crédito, o valor do imóvel é definido com base no Caderno de Preços para os terrenos urbanos (Norte Energia, 2013a). Para fins de cálculo, foram selecionados 132 pontos de referência com características diferenciadas no que diz respeito à localização (centro/periferia), área, vocação (residencial/comercial), risco ${ }^{3}$ (nulo, médio ou forte) e registro (posse/ contrato). Para o cálculo do preço final, outras variáveis são utilizadas, como tipo de terreno (gleba/lote), padrão, infraestrutura, edificação e o mês de referência (no caso Jan/2013). No que tange à indenização em dinheiro, uma pequena parcela das famílias elegeu essa modalidade na área urbana (17\%), o que se deve, em grande medida, ao fato de que o equivalente em dinheiro seria insuficiente para adquirir moradia na cidade. Com a intensa migração a partir de 2010, os preços dos terrenos e aluguéis atingiram níveis altíssimos, chegando a superar em mais de três vezes os valores de mercado. Até 2013 foram registrados mais de 40 ações na justiça relacionadas aos valores de indenizações (Jornal Amazônia, 2013).

Com a opção pelo reassentamento, mais de 22 mil pessoas deverão ser assentadas em mais de 6 mil lotes urbanos. Os critérios utilizados pela Norte Energia para a seleção dessas áreas são: localização (priorizando áreas até $2 \mathrm{~km}$ do local de origem do reassentado), acessibilidade (comunicação com o entorno a partir de um sistema viário funcional), topografia favorável (além de estar acima da cota de segurança, o terreno deve possuir poucas variações topográficas, com condições para uma drenagem adequada), conexão com as estruturas básicas mínimas

\footnotetext{
${ }^{3}$ Indica se o imóvel encontra-se em local com risco forte, médio ou nulo de inundação, analisada na forma qualitativa (Norte Energia, 2013a).
} 


\section{Revista Nacional de}

(saúde, educação e serviços básicos), bem como as condições de aquisição e disponibilidade no mercado.

Quando da elaboração do Plano Básico Ambiental (PBA), que delimita as ações para a execução da obra e das medidas mitigatórias, algumas das áreas preferenciais definidas pela Norte Energia para o reassentamento urbano já haviam sido ocupadas por empresas imobiliárias, incorporadoras e usuários particulares (Norte Energia, 2011). Assim, das 17 áreas anteriormente selecionadas, apenas 5 foram de fato utilizadas para Reassentamento Urbano Coletivo, as quais são definidas na tabela abaixo:

TABELA 1 - Características das Áreas de Reassentamento Urbano Coletivo

\begin{tabular}{c|c|c|c}
\hline RUCs & $\begin{array}{c}\mathbf{N}^{\circ} \text { de Lotes } \\
\text { (Estimativo) }\end{array}$ & $\begin{array}{c}\text { Residenciais } \\
\text { RUC }\end{array}$ & Vila Residencial \\
\hline Jatobá & 1286 & 1270 & 16 \\
\hline São Joaquim & 1041 & 937 & 104 \\
\hline Casa Nova & 453 & 453 & - \\
\hline Água Azul & 775 & 775 & - \\
\hline Laranjeiras & 545 & 545 & - \\
\hline TOTAL & $\mathbf{4 1 0 0}$ & $\mathbf{3 9 8 0}$ & $\mathbf{1 2 0}$ \\
\hline
\end{tabular}

Fonte: Norte Energia, 2013b.

No que diz respeito à tipologia das casas, o Plano Básico Ambiental havia definido duas classes de unidades habitacionais: Classe 1, em que se admite o parcelamento na forma de loteamento unifamiliar e Classe 2, em que se admite o parcelamento em lotes maiores, condominiais, para edificações multifamiliares de até cinco pavimentos. Em ambos os casos, a área mínima de construção seria de $60 \mathrm{~m}^{2}$ com 2 ou 3 dormitórios, em lotes individuais de $300 \mathrm{~m}^{2}$. Posteriormente, passou-se a admitir apenas um modelo de casa padrão com $63 \mathrm{~m}^{2}$ (2 quartos, 1 suíte, sala, cozinha, banheiro social, varanda e área de serviço) e outros dois modelos de casa adaptado para pessoas com deficiência. Tal alteração gerou questionamentos por representantes das pessoas atingidas e movimentos sociais locais, uma vez que se esperava a garantia da proposta anteriormente definida no PBA. A Norte Energia alega, contudo, que a tipologia padrão está em conformidade 


\section{Revista Nacional de}

para o atendimento de cada família cadastrada, ou seja, se na antiga residência moravam três famílias, cada uma dessas famílias deverá ser indenizada com uma unidade habitacional padrão.

Outro item que gerou questionamentos foi o material de construção das residências: de concreto armado, produzido a partir de uma tecnologia que reduz o tempo de construção e o número de trabalhadores necessários. Os futuros moradores ficaram preocupados com a existência de fissuras em alguns modelos implantados pela empresa. Outra dúvida seria em relação à sensação térmica no interior das casas que, para a população, seria maior que em casas de madeira ou alvenaria. Para estes casos, a Norte Energia argumentou que as residências possuem conforto termoacústico superior a casas de alvenaria e que as fissuras foram encontradas apenas em alguns modelos criados para fins de apresentação. O embate entre a empresa e movimentos sociais é muito presente e motiva vários conflitos na escala local.

Para acompanhamento das atividades foi criado em abril de 2012 o Comitê de Acompanhamento do Projeto de Reassentamento Urbano, com 15 representações da sociedade civil, como associação de moradores, executivo e legislativo local, além de órgãos como Corpo de Bombeiros e associações de direitos humanos. As reuniões são realizadas de forma regular e nelas são discutidos pontos como: andamentos das obras e dos projetos de habitação, cadastro socioeconômicos, atividades de reassentamento e outros itens ligados ao tema.

O processo de reassentamento iniciou em 2013 e acontece de forma progressiva, conforme as etapas das obras de habitação são concluídas. Os atrasos no cronograma geram consequências negativas para a população diretamente afetada. Uma delas diz respeito ao próprio ciclo das cheias do rio Xingu (entre dezembro e março) quando a população das áreas mais vulneráveis adaptam pontes para possibilitar o acesso às residências. No início de 2014, sem perspectivas de mudança, a população não se antecipou ao período de cheias e mais de 160 famílias ficaram desalojadas em (em torno de 1200 pessoas). Diante da 


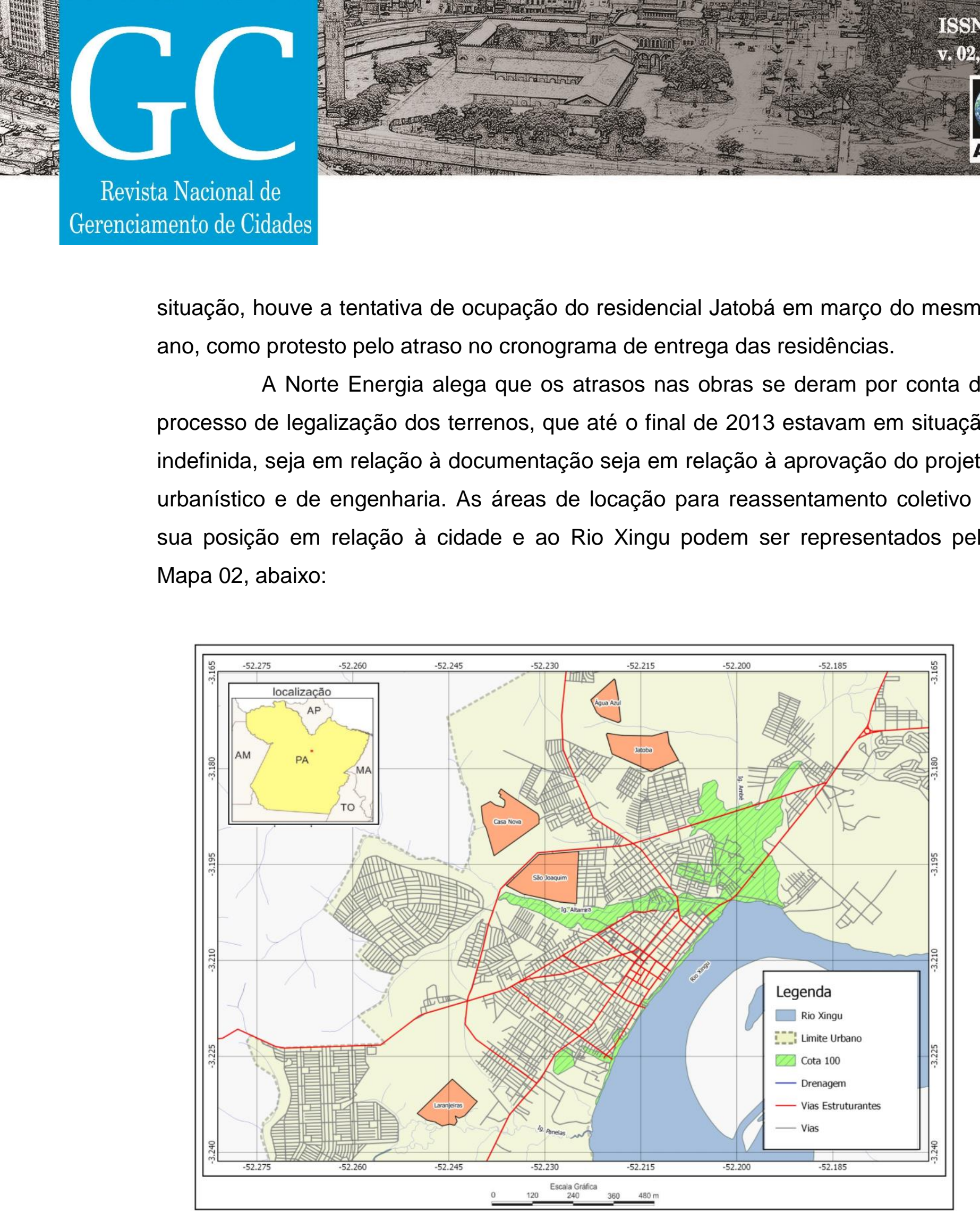

situação, houve a tentativa de ocupação do residencial Jatobá em março do mesmo ano, como protesto pelo atraso no cronograma de entrega das residências.

A Norte Energia alega que os atrasos nas obras se deram por conta do processo de legalização dos terrenos, que até o final de 2013 estavam em situação indefinida, seja em relação à documentação seja em relação à aprovação do projeto Mapa 02, abaixo:

Mapa 02 - Localização das áreas de Reassentamento Urbano Coletivo - RUCs Fonte: GEDTAM, 2014

É possível perceber no Mapa 02 que existe uma relativa distância entre as áreas de reassentamento e urbano coletivo e o limite altimétrico de inundação por ocasião da construção da barragem (Cota 100). Há, também, conformidade acerca da distância máxima de deslocamento das famílias de $2 \mathrm{~km}$ em relação ao local de 


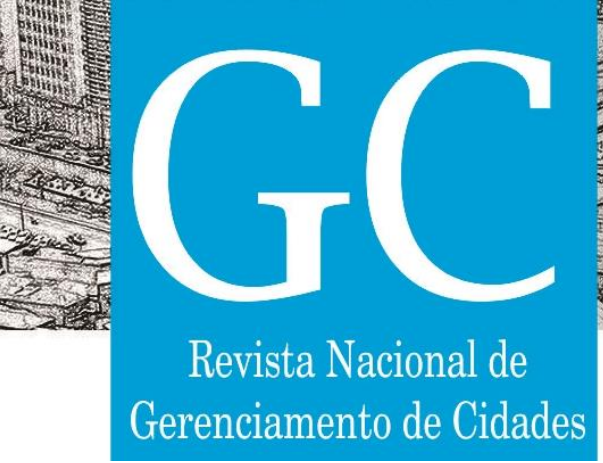

Por outro lado, algumas ponderações precisam ser feitas em relação ao andamento dos processos e seus desdobramentos. A primeira questão diz respeito ao fato de as intervenções urbanísticas atenderem a pontos específicos da área urbana da cidade: a ADA Urbana, com modificações mais profundas na paisagem e as áreas de reassentamento urbano. Os sistemas de água e esgoto atenderão ao que foi planejado no PBA, mas não abrangem as áreas de expansão da cidade. Com a migração em massa, espera-se a chegada de mais de noventa mil pessoas para a região, grande parte delas com destino à área urbana. Por esse motivo, não se pode excluir a possibilidades de criação de novos aglomerados subnormais caso as instituições não realizem uma gestão adequada da habitação, incluindo a oferta de novas moradias.

Outro ponto importante diz respeito aos atrasos no cronograma para 0 reassentamento urbano, que gerou expectativas, frustrações e, com elas, ações de protesto por parte da população diretamente afetada. Dentre outros motivos, esses atrasos estão ligados: 1) ao processo jurídico de regularização fundiária que, tal como no resto do país, é moroso e repleto de meandros; 2) à competição com o mercado imobiliário, uma vez que as incorporadoras e proprietários fundiários agem no sentido de barganhar um preço mais elevado da terra, muitas vezes dificultando as negociações; 3) as dificuldades de relações interinstitucionais com vistas a mobilizar as forças necessárias para os empreendimentos de habitação.

Diante deste quadro, fica cada vez mais evidente a necessidade de se ter um marco jurídico-político diferenciado para as áreas que são objeto de grandes obras de infraestrutura, como projetos hidrelétricos. Os impactos destes empreendimentos são de grande envergadura e provocam consequências permanentes nos espaços em que se instalam. A necessidade de uma maior intervenção e uma regulação diferenciada, especialmente no campo imobiliário, deve ser considerada tendo em vista resguardar a integridade das populações diretamente afetadas. Estes sujeitos, em muitos casos, acabam sofrendo consequências negativas de um projeto cunhado em nome do desenvolvimento social e ambiental e, por isso, devem ser respeitados em sua integridade. 


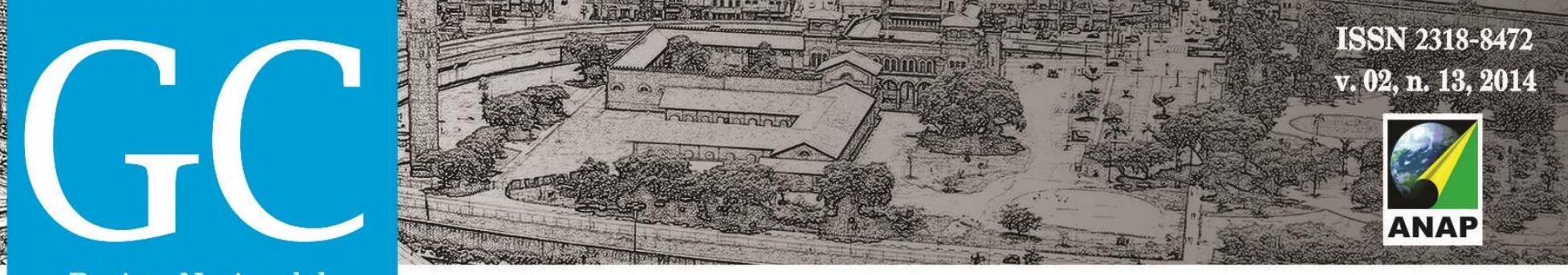

Revista Nacional de

Gerenciamento de Cidades

\section{REFERÊNCIAS}

BRASIL. MINISTÉRIO DAS MINAS E ENERGIA. Relatório de Impacto ambiental: aproveitamento hidrelétrico Belo Monte. Brasília, Maio de 2009.

COHEN, S. C. et al. Habitação saudável e ambientes favoráveis à saúde como estratégia de promoção da saúde. Ciência \& Saúde Coletiva, 12(1):191-198, 2007.

GEDTAM - Grupo de estudos desenvolvimento e dinâmicas territoriais na Amazônia. Malha urbana de Altamira - 2014 [Mapa]. Altamira; 2014b.

IBGE. Instituto Brasileiro de Geografia e Estatística. Aglomerados Subnormais: primeiros resultados. Rio de Janeiro: IBGE, 2010a.

IBGE. Instituto Brasileiro de Geografia e Estatística. Sinopse preliminar do censo demográfico. Rio de Janeiro: IBGE, 2010a.

JORNAL AMAZÔNIA. Indenização irrisória e casas com "prazo de validade" assustam moradores de Altamira. 17 de agosto de 2013. Obtido em http://amazonia.org.br.

MINISTÉRIO DAS CIDADES. Curso de gestão ambiental em urbanização de assentamentos precários. Brasília - DF, 2007.

NORTE ENERGIA S.A. Apresentação da Comissão de Reassentamento Urbano. Altamira-Pa. 2012. 28 slides: color. Slides gerados a partir do software PowerPoint.

NORTE ENERGIA S.A. Caderno de Preços: zona urbana de Altamira. Maio de 2013a.

NORTE ENERGIA S.A. Projeto Básico Ambiental da Usina Hidrelétrica de Belo Monte: Planos programas e projetos. Agosto de 2010.

NORTE ENERGIA S.A. Relatórios parciais. ITEM 5.1.2: REASSENTAMENTO URBANO. Maio de 2013b.

TEIXEIRA, J. C; HELLER, L. Fatores ambientais associados à diarreia infantil em áreas de assentamento subnormal em Juiz de Fora, Minas Gerais. Rev. Bras. Saúde Matern. Infant., Recife, 5 (4): 449-455, out. / dez., 2005

UMBUZEIRO. A. U. B; UMBUZEIRO, U. M. U. Altamira e sua história. 4ed. Belém, Ponto Press, 2012. 